\title{
Epidemiology and time trends of distal forearm fractures in adults - a study of 11.2 million person-years in Sweden
}

\author{
Daniel Jerrhag $^{1^{*}}$ (D, Martin Englund ${ }^{2,3}$, Magnus K. Karlsson $^{1}$ and Bjorn E. Rosengren ${ }^{1}$
}

\begin{abstract}
Background: A distal forearm fracture is a very common injury causing both suffering and substantial health care costs. The incidence of this fracture type seemed to increase worldwide until the middle 1980's, but thereafter most reports have shown stable or decreasing rates. As few large studies have been presented lately we aimed to describe recent epidemiology and time trends of distal forearm fractures in adults. We paid special attention to fractures in working ages as they present challenges in terms of treatment and costs for sick-leave, and have not previously been thoroughly investigated.

Methods: By use of population data from Statistics Sweden and official in- and out-patient register data of men and women ( $\geq 17$ years) in Sweden (Skåne region), we ascertained distal forearm fractures and estimated age- and sex-specific rates and time-trends from year 1999 to 2010 (11.2 million person-years (py)).

Results: The total incidence rate was 278 per 100,000 py (31,233 fractures) with 23\% higher annual numbers 2010 compared with 1999. An increase in the annual age standardized incidence was found in men, $+0.7 \%$ per annum ( $95 \%$ confidence interval $(\mathrm{Cl}) 0.1,1.4)$, and women, $+0.9 \%$ ( $95 \% \mathrm{Cl} 0.5,1.3)$, driven mainly by an increasing incidence in working ages (17-64 years). Also, expected demographic changes including a 25\% population increase may result in 38\% more fractures until 2050, compared to 2017.

Conclusions: The incidence of distal forearm fractures in adults in southern Sweden is increasing, mainly driven by an increase in working ages. In combination with expected demographic changes these findings may present substantial challenges for the future.
\end{abstract}

Keywords: Epidemiology, Time-trends, Wrist fracture, Distal radius fracture, Forecast

\section{Background}

The distal forearm fracture is a common orthopedic injury. The consequences for the individual patient depend on factors such as age, fracture pattern and occupation. In epidemiological studies the age rate curve has been found to be bimodal, with highest incidences found in children and elderly $[1,2]$.

In young adulthood and middle age the distal forearm fracture is less common than in childhood and in the elderly, but fracture patterns can be severe with consequent loss of function or absence from work. The higher

\footnotetext{
* Correspondence: Daniel.Jerrhag@med.lu.se

${ }^{1}$ Clinical and Molecular Osteoporosis Research Unit, Departments of Clinical Sciences and Orthopedics Malmö, Skåne University Hospital, Lund University, SE 20502 Malmo, Sweden

Full list of author information is available at the end of the article
}

incidence rates of this fracture type in the elderly result in substantial suffering as well as health care costs.

We have earlier found that the incidence of distal forearm fractures among children is increasing in the Skåne region, Sweden [3]. In adults, however, few larger studies of distal forearm fracture epidemiology have been presented recently $[4,5]$ and none with focus on workingage individuals. To provide politicians and public health planners with current data, we aimed to, in the Skåne region, Sweden (i) describe present epidemiology of distal forearm fractures in the adult population, specifically also in the working-age population, (ii) estimate time-trends during the most recent decade, and (iii) make a forecast to estimate the number of fractures the decades to come. 


\section{Methods}

The Skåne Healthcare Register (SHR) is a register covering in- and outpatient health care provided to residents of Skåne, the southernmost region of Sweden from year 1998. The region includes both urban and rural areas and had in year 2010 a total adult ( $\geq 17$ years) population of about 1.0 million. From year 1999 to 2010 we used the SHR to ascertain distal forearm fractures in adults ( $\geq 17$ years) residing in the region (11.2 million py) by using physician-set diagnostic codes according to the Swedish version of the International Classification of Diseases (ICD) 10 system (S52.50, S52.51, S52.60, S52.61). Bilateral fractures were counted as only one fracture as the database does not include information about side. The washout period was set to 1 year (365 days) for each fracture and unique individual and we consequently also included year 1998 data to create a reference for washouts year 1999. From the complete data set we estimated sex-specific incidence rates per 100,000 py using the cumulative annual adult population, in one year age classes from Statistics Sweden as denominator (population at risk) [6]. For estimation of temporal trends, we tabulated data by year and used Poisson regression of annual direct age-standardized incidence rates (with the average population during the examined years as the standard population) and included $95 \%$ confidence intervals $(95 \% \mathrm{CI})$ to describe uncertainty. The validity of the register, in terms of distal forearm fractures, has previously been examined with a sensitivity of $90 \%$ and positive predictive value of $94 \%$ for the register data compared to gold standard [7].
To estimate the number of distal forearm fractures in the whole of Sweden the forthcoming decades, the overall incidence in 1-year age groups during the examination period from 1999 to 2010 from the Skåne region was applied to demographic forecasts from Statistics Sweden for the years 2017-2050 [8].

We used SAS system v 9.2, SPSS v17.0, and Microsoft Excel 2003 for data management and statistical calculations. All tests were two-tailed and we considered a $p$-value lower than 0.05 to be statistically significant. The study has been approved by the Ethical Review Board (ERB) at Lund University (2011/432).

\section{Results}

From year 1999 to 2010 we identified 31,233 distal forearm fractures (male to female ratio 1:3) during 11.2 million py. This represents an overall incidence of 278 per 100,000 py (Table 1 ).

Adults in working ages (17-64 years) contributed to 15,052 fractures (48\% of all fractures, male to female ratio 1:1.5). Correspondingly, those older than 64 years contributed to 16,181 fractures (52\% of all, male to female ratio 1:6.5). From 1999 to 2010 the overall annual number of distal forearm fractures increased from 2368 to 3089 , with underlying increases in both men (from 589 to 766) and women (from 1779 to 2323). An additional file shows the number of persons at risk, and the number of fractures more in detail (additional file 1).

There was also a significant increase in the annual age-standardized incidence in both men $(+0.7 \%$ per annum, 95\% CI 0.1, 1.4), and women $(+0.9 \%, 95 \%$ CI 0.5 ,

Table 1 Population at risk, number of fractures and overall wrist fracture incidence

\begin{tabular}{|c|c|c|c|c|c|c|}
\hline \multirow{2}{*}{$\begin{array}{l}\text { Age } \\
\text { stratum } \\
\text { (years) }\end{array}$} & \multicolumn{3}{|l|}{ Men } & \multicolumn{3}{|l|}{ Women } \\
\hline & At risk & Fractures & Incidence & At risk & Fractures & Incidence \\
\hline$\geq 17$ & $5,478,970$ & 8217 & 150 & $5,762,155$ & 23,016 & 399 \\
\hline $17-64$ & $4,412,748$ & 6045 & 137 & $4,342,588$ & 9007 & 207 \\
\hline$\geq 65$ & $1,066,222$ & 2172 & 204 & $1,419,567$ & 14,009 & 987 \\
\hline $17-49$ & $3,081,881$ & 4106 & 133 & $3,016,896$ & 3425 & 114 \\
\hline$\geq 50$ & $2,397,089$ & 4111 & 171 & $2,745,259$ & 19,591 & 714 \\
\hline $17-19$ & 264,337 & 781 & 295 & 255,140 & 343 & 134 \\
\hline $20-29$ & 897,345 & 1152 & 128 & 889,840 & 835 & 94 \\
\hline $30-39$ & 983,138 & 946 & 96 & 951,017 & 954 & 100 \\
\hline $40-49$ & 937,061 & 1227 & 131 & 915,592 & 1293 & 141 \\
\hline $50-59$ & 920,560 & 1287 & 140 & 916,685 & 3201 & 349 \\
\hline $60-69$ & 734,078 & 1117 & 152 & 757,112 & 4699 & 621 \\
\hline 70-79 & 476,240 & 843 & 177 & 588,380 & 5269 & 896 \\
\hline 80-89 & 235,815 & 717 & 304 & 399,501 & 4989 & 1249 \\
\hline$\geq 90$ & 30,398 & 147 & 484 & 88,891 & 1433 & 1612 \\
\hline
\end{tabular}

Different age-strata (years) and incidence per 100,000 py during 1999-2010 in the Skåne region, Sweden 
1.3). For adults in working ages (17-64 years) the incidence increased significantly for both men $(+0.8 \%, 95 \%$ CI $0.02,1.5)$ and women $(+2.1 \%, 95 \%$ CI $1.5,2.8)$ while it was stable in their counterparts $\geq 65$ years. Detailed data including other relevant age groups are presented in Table 2.

Even though the Swedish population $\geq 17$ years is estimated to increase by only $25 \%$ from $8,110,000$ (year 2017) to $10,100,000$ (year 2050) we project an increase in number of forearm fractures by $38 \%$ from 22,600 (year 2017) to 31,000 (year 2050) due to shifts in age structure (Fig. 1). In working ages (17-64 years) the total number of fractures is projected to increase from 10,400 to 12,500, representing an increase by $20 \%$. In the age-group $\geq 65$ years the number of fractures is projected to increase from 12,200 to 18,600 , an increase by $52 \%$ (Fig. 2).

\section{Discussion}

In our study of 11.2 million py in a well-defined Swedish population we found that the age-standardized incidence in both adult ( $\geq 17$ years) men and women increased significantly from year 1999 to 2010. This was driven mainly by an increase in working ages (17-64 years). With an increasing population and the expected demographic changes until year 2050 we project the number of distal forearm fractures to increase by $38 \%$ in Sweden

Table 2 Annual change in age standardized rates in different age-strata in the Skåne County 1999-2010

\begin{tabular}{|c|c|c|}
\hline \multirow[b]{2}{*}{ Age stratum (years) } & \multicolumn{2}{|c|}{ Annual percent change $(95 \% \mathrm{Cl})$} \\
\hline & $\overline{M e n}$ & Women \\
\hline \multicolumn{3}{|l|}{ Primary analyses } \\
\hline$\geq 17$ & $+0.7(0.1,1.4)$ & $+0.9(0.5,1.3)$ \\
\hline $17-64$ & $+0.8(+0.0,1.5)$ & $+2.1(1.5,2.8)$ \\
\hline$\geq 65$ & $+0.5(-0.7,1.8)$ & $+0.1(-0.3,0.6)$ \\
\hline \multicolumn{3}{|l|}{ Secondary analyses } \\
\hline $17-49$ & $+0.7(-0.2,1.6)$ & $+1.0(-0.0,1.9)$ \\
\hline$\geq 50$ & $+0.8(-0.1,1.7)$ & $+0.5(0.1,0.9)$ \\
\hline \multicolumn{3}{|l|}{ Tertiary analyses } \\
\hline $17-19$ & $+1.7(-0.4,3.8)$ & $+2.3(-0.8,5.5)$ \\
\hline $20-29$ & $+1.3(-0.4,3.0)$ & $+0.0(-1.9,2.0)$ \\
\hline $30-39$ & $+0.4(-1.4,2.3)$ & $-0.5(-2.3,1.3)$ \\
\hline $40-49$ & $-0.2(-1.8,1.4)$ & $+2.3(0.7,4.0)$ \\
\hline $50-59$ & $+2.0(0.4,3.7)$ & $+3.4(2.3,4.4)$ \\
\hline $60-69$ & $-0.7(-2.4,1.0)$ & $+1.7(0.9,2.6)$ \\
\hline $70-79$ & $+0.0(-1.9,2.0)$ & $+2.0(1.2,2.9)$ \\
\hline $80-89$ & $+2.1(-0.1,4.3)$ & $+0.2(-0.6,1.0)$ \\
\hline$\geq 90$ & $-0.8(-5.4,4.0)$ & $+0.6(-0.9,2.1)$ \\
\hline
\end{tabular}

from 2017 to year 2050, even though the actual number of citizens is only estimated to increase by $25 \%$.

Distal forearm fracture rates have been superintended episodically and most studies agree on an increase from the 1950's to the 1980's [2, 9-12]. After the 1980's some studies have reported decreasing or stable adult distal forearm fracture rates $[5,13-20]$, whilst some recent reports, from Denmark and Taiwan, infer an increasing incidence [4, 21] (Fig. 3a, b).

A new large British study [20] during years 1988-2012 however reports a lower incidence in the entity radius/ulnar fractures (not only distal forearm fractures) than that we found for only distal forearm fractures. Since definition of fracture, ascertainment method, geographical regions and age stratification differ substantially between studies, direct comparisons are difficult (Tables 3 and 4).

We therefore primarily compared our results to earlier reports from the Skåne region, Sweden [2, 9, 13] (Fig. 3a, b). Jonsson et al. [13] reported a lower incidence in both genders in the adult population in Malmö (the largest city in the Skåne region) 1991-1992 compared to 1980-1981. In our data from the period 1999-2010, the incidence in men $\geq 17$ years ( 150 per 100,000 py) were at the level of those for Malmö 1980-1981 but higher than those from 1991 to 1992. In contrast, for women, the incidence was lower during 1999-2010 (339 per 100,000 py), than in Jonsson et al. 1991-1992 [13]. In the north-eastern part of the Skåne region, Brogren et al. [22] reported an incidence in men $\geq 19$ years of 120 per 100,000 py and in women of 390 per 100,000 py in year 2001. In Finland, Flinkkilä et al. reported an incidence for men and women $\geq 16$ years, of 147 and 363 per 100,000 py, respectively, in year 2008 . Both Brogren et al. and Flinkkilä et al. base their results on fracture ascertainment through radiographs and medical charts and their results are similar to ours.

In our study we found a significant annual increase in the age standardized distal forearm fracture rate in adult men and women. As a distal forearm fracture has been found to be an indicator of osteoporosis [23] and also forecast subsequent fractures, [24, 25] these results may have implication for the future fracture burden. Our results are in some contrast to Wilcke et al. [5] who in Stockholm, Sweden, found a decreasing forearm fracture rate from year 2004 to 2010 in individuals $\geq 65$ years of age. However, their findings must be interpreted with care as they included only one fracture per individual, rendering a decreasing population at risk with successive years without a corresponding decrease in the denominator and without adjustment for lower risks in those who remained eligible. On the other hand Abrahamsen et al. [4] in a recent large register based study in Denmark, found a higher incidence compared to earlier. Their reported incidence for men (153 per 100,000 py) 


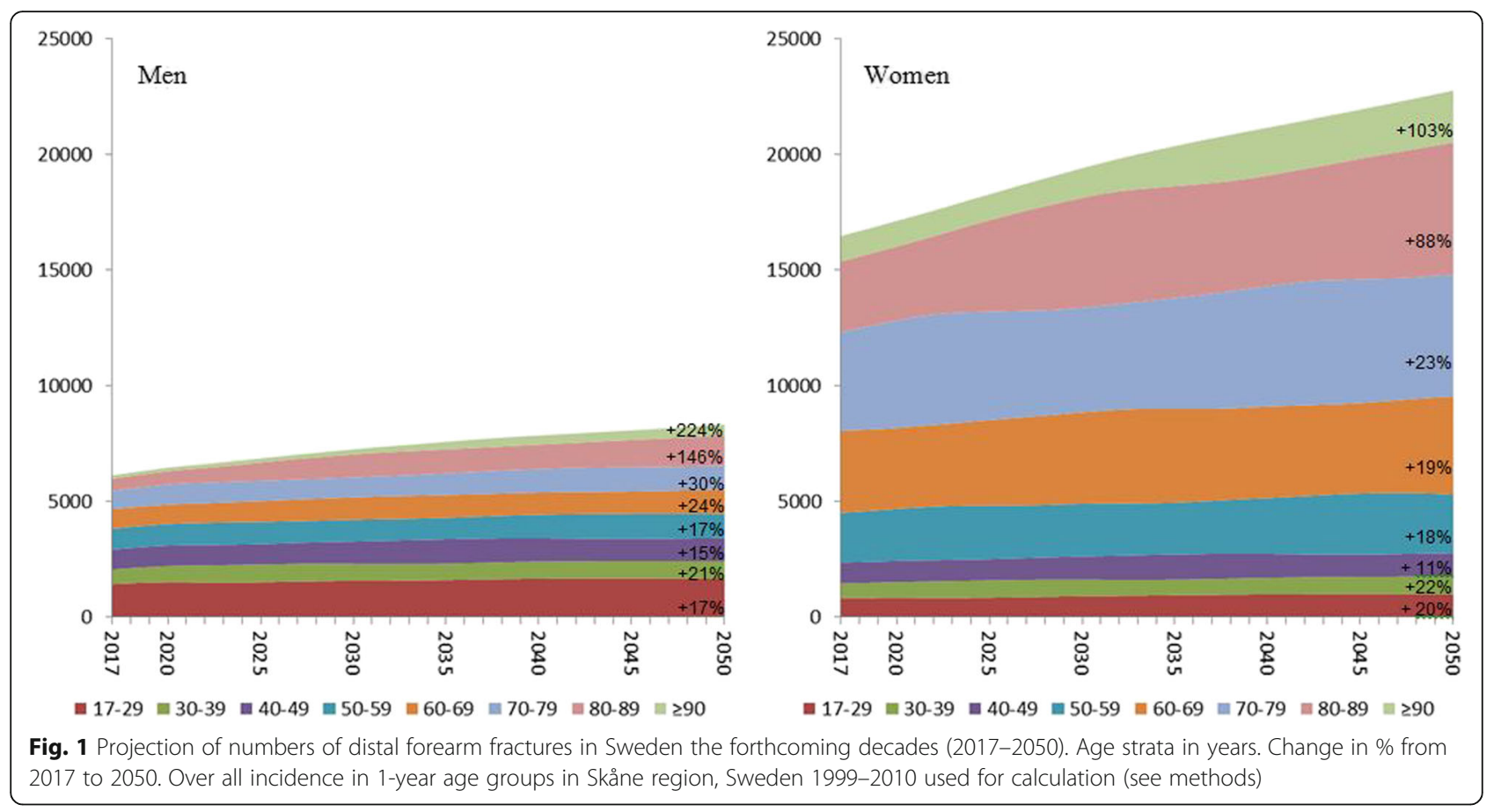

was nearly the same as we found, but for women (530 per 100,000 py) somewhat higher (Fig. 3a, b).

The reasons behind the increase in incidence we found during 1999-2010 are not examined in this study but several factors may have contributed including an increased prevalence of osteoporosis. Trend data available for osteoporosis in the Skåne region, Sweden [26-28], do however not indicate this. More recent studies from other countries including Finland and USA, actually point in the opposite direction with an increasing time trend in bone mineral density (BMD) [29, 30]. A more strict postmenopausal estrogen prescription compared to earlier may have contributed to an increased fracture incidence but this effect is likely small as the incidence is increasing in both men and women. In Sweden, as in many other countries, body mass index (BMI) is
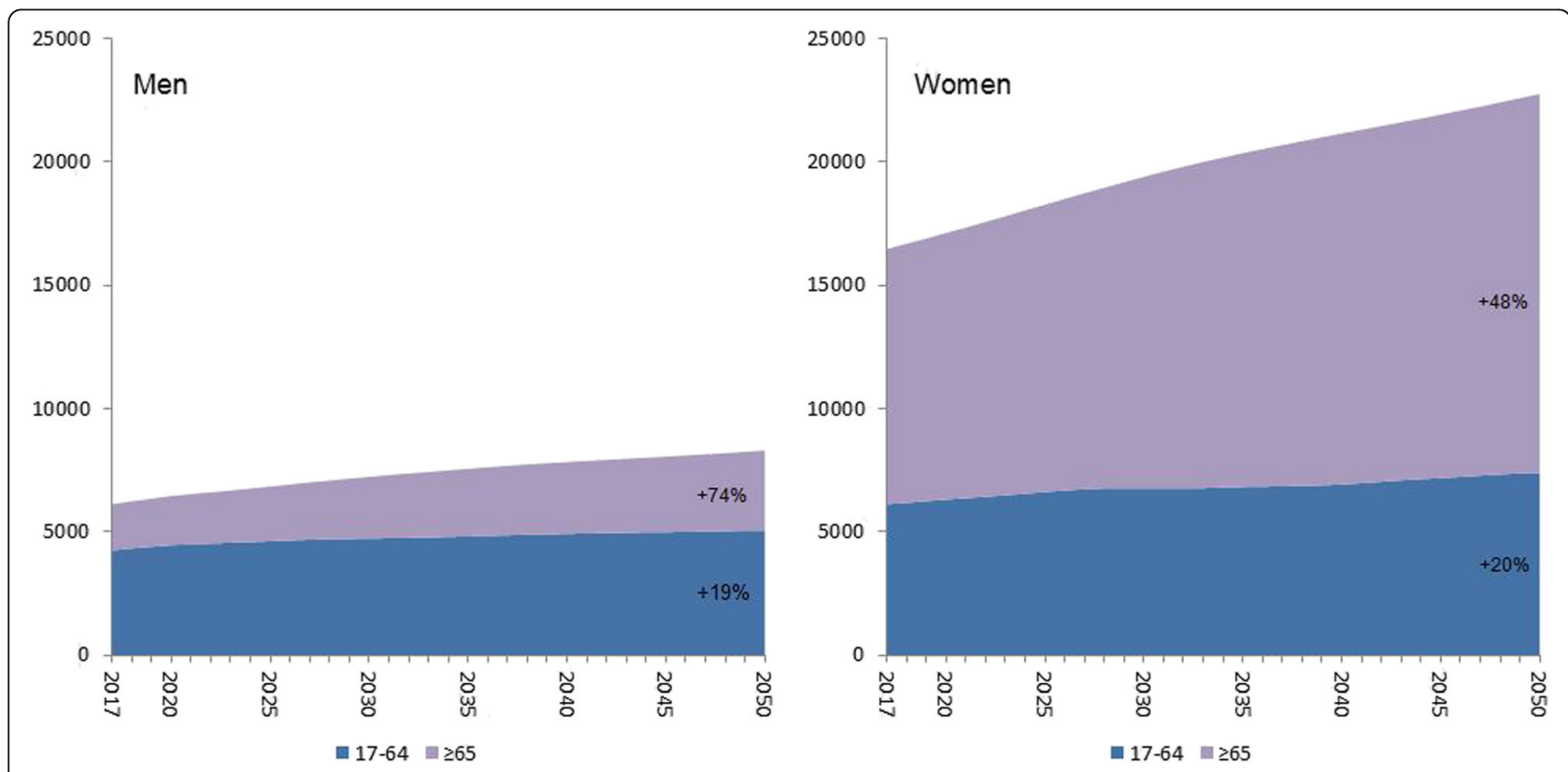

Fig. 2 Projection of numbers of distal forearm fractures in Sweden in working and non-working ages. Age strata in years. Change in \% from 2017 to 2050. Over all incidence in 1-year age groups in Skåne region, Sweden 1999-2010 used for calculation (see methods) 


\section{a}

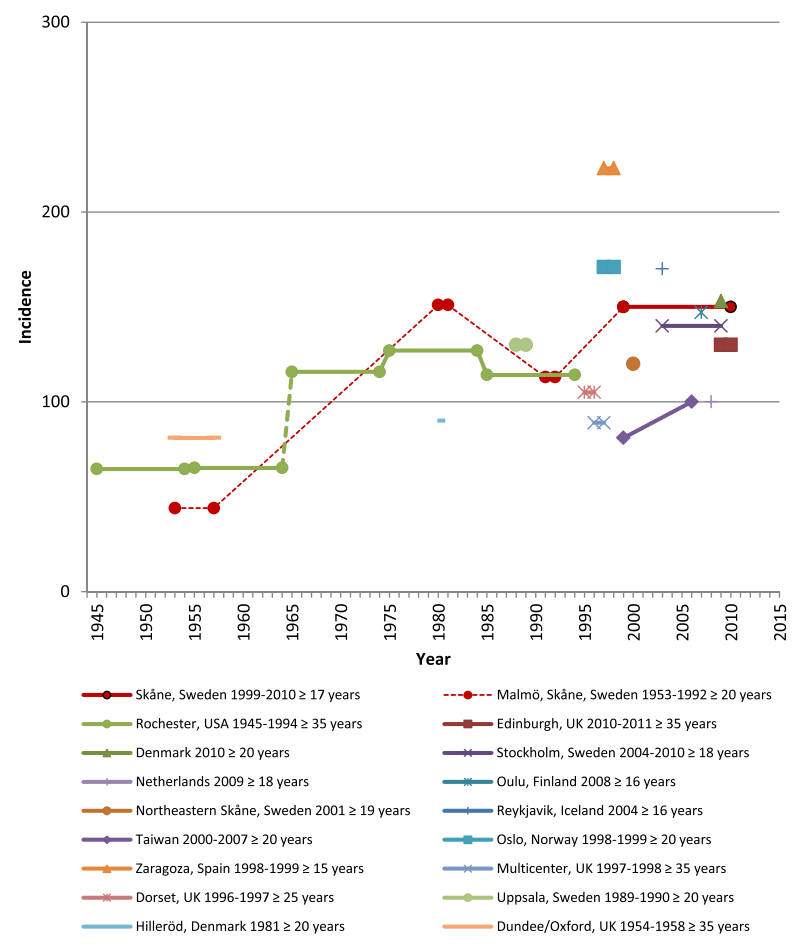

b

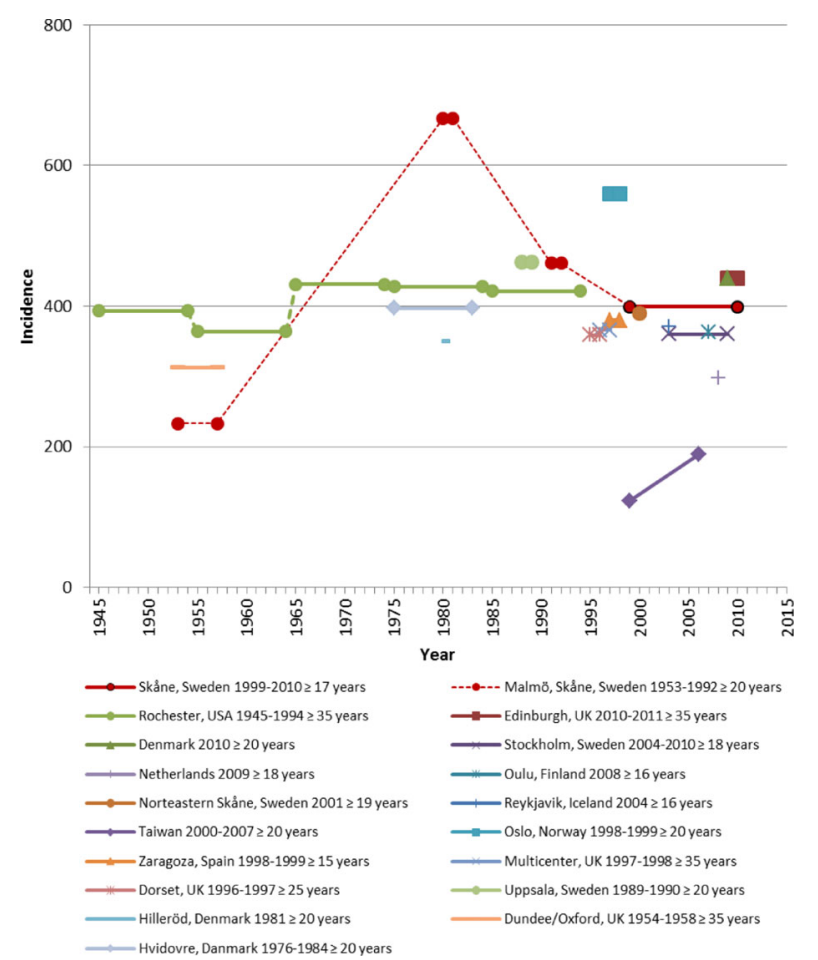

Fig. 3 a. Reported incidence of distal forearm fractures in men per 100,000 py during the last 6 decades. $\mathbf{b}$. Reported incidence of distal forearm fractures in women per 100,000 py during the last 6 decades. $[2,4,5,9,11,13-18,21,22,39-45]$

Table 3 Reported incidence of distal forearm fractures in adults ( $\geq 50$ years) during 7 decades

\begin{tabular}{llll}
\hline Population at risk & Year & \multicolumn{2}{l}{ Incidence } \\
\cline { 3 - 4 } & & Men & Women \\
\hline Skåne, Sweden $^{\text {a }}$ & $1999-2010$ & 171 & 712 \\
Denmark $^{\mathrm{a}}$ [4] & 2010 & 203 & 926 \\
Austria $^{\mathrm{b}}$ [46] & 2010 & 162 & 607 \\
Oulu, Finland $^{\mathrm{a}}$ [16] & 2008 & 223 & 710 \\
Netherlands $^{\mathrm{a}}$ [44] & 2009 & 147 & 612 \\
Kristiansand, Norway $^{\mathrm{b}}$ [47] & $2004-2005$ & 189 & 751 \\
Northeastern Skåne, Sweden $^{\text {a }}$ [22] & 2001 & 152 & 677 \\
Austria $^{\mathrm{b}}$ [46] & 1999 & 171 & 709 \\
Oslo, Norway $^{\mathrm{a}}$ [14] & $1998-1999$ & 254 & 1098 \\
Malmö, Sweden $^{\mathrm{a}}$ [13] & $1991-1992$ & 157 & 827 \\
Uppsala, Sweden $^{\mathrm{a}}$ [42] & $1989-1990$ & 217 & 970 \\
Malmö, Sweden $^{\text {ac }}$ [9] & $1980-1981$ & 158 & 462 \\
Hvidovre, Danmark $^{\mathrm{a}}$ [45] & $1976-1984$ & - & 695 \\
Hilleröd, Denmark $^{\mathrm{a}}$ [1 1] & 1981 & 116 & 824 \\
Oslo, Norway $^{\mathrm{a}}$ [40] & 1979 & 234 & 1137 \\
Malmö, Sweden $^{\mathrm{a}}$ [2] & $1953-1957$ & 53 & 510 \\
\hline
\end{tabular}

Incidence per 100,000 py

${ }^{a}$ Crude incidence

${ }^{\mathrm{b}} \mathrm{Age}$ standardized incidence

'Numbers derived from Jónsson et al. [13] increasing [31]. The importance of BMI for fracture risk has been known since long but recent insights have inferred that a higher BMI, apart from giving a lower risk for hip fracture, also confers a higher risk for upper extremity fracture [32].

Apart from consequences for the individual there are other implications of fractures. As the distal forearm fracture is the most common of fractures, even a minor increase in occurrence could substantially impact health care resource demands and public health costs. This would be especially true if the increase occurs in working ages where patients need sick-leave, depending on occupation, for 5-12 weeks or more. Any permanent loss of function may also result in inability to work with loss of competence for both employer, and society. The mean fracture-related cost of a distal forearm fracture in Sweden, in patients $\geq 50$ years, during the year following the diagnosis, has been estimated to $€ 2147$ in 2005 [33]. This was however just before the volar locking plate became the dominating surgical treatment [19] and therefore cost per treated patient is supposedly higher now.

As the volar locking plate is a more expensive treatment than other alternatives like casting, wire fixation and external fixation a question needed to put forward is whether it should be the gold standard procedure or not 
Table 4 Reported incidence of distal forearm fractures in adults in different countries or areas

\begin{tabular}{|c|c|c|c|c|}
\hline \multirow[t]{2}{*}{ Population at risk } & \multirow[t]{2}{*}{ Year } & \multirow[t]{2}{*}{ Age (Years) } & \multicolumn{2}{|c|}{ Incidence } \\
\hline & & & Men & Women \\
\hline Skåne, Sweden ${ }^{a}$ & 1999-2010 & $\geq 17$ & 150 & 399 \\
\hline Edinburgh, UK ${ }^{\mathrm{a}}$ [41] & 2010-2011 & $\geq 35$ & 130 & 440 \\
\hline Denmark $^{\mathrm{a}}[4]$ & 2010 & $\geq 20$ & 153 & 530 \\
\hline Stockholm, Sweden ${ }^{a}[5]$ & 2004-2010 & $\geq 18$ & 140 & 360 \\
\hline Oulu, Finland ${ }^{\mathrm{a}}[16]$ & 2008 & $\geq 16$ & 147 & 363 \\
\hline Netherlands ${ }^{\mathrm{a}}[44]$ & 2009 & $\geq 18$ & 100 & 298 \\
\hline Taiwan $^{a}$ [21] & 2007 & $\geq 20$ & 100 & 189 \\
\hline Reykjavik, Iceland ${ }^{\mathrm{a}}$ [17] & 2004 & $\geq 16$ & 170 & 370 \\
\hline Northeastern Skåne, Sweden ${ }^{\mathrm{a}}$ [22] & 2001 & $\geq 19$ & 120 & 390 \\
\hline Taiwan $^{a}$ [21] & 2000 & $\geq 20$ & 81 & 123 \\
\hline Oslo, Norway ${ }^{\mathrm{a}}[14]$ & 1998-1999 & $\geq 20$ & 171 & 560 \\
\hline Dorset, UK ${ }^{\mathrm{a}}[18]$ & 1996-1997 & $\geq 25$ & 105 & 359 \\
\hline Zaragoza, Spain ${ }^{\mathrm{a}}$ [39] & 1998-1999 & $\geq 15$ & 223 & 380 \\
\hline Multicenter, UK ${ }^{\mathrm{a}}$ [43] & 1997-1998 & $\geq 35$ & 90 & 368 \\
\hline Malmö, Sweden ${ }^{a}$ [13] & 1991-1992 & $\geq 20$ & 113 & 461 \\
\hline Rochester, Minnesota ${ }^{\mathrm{b}}[15]$ & 1985-1994 & $\geq 35$ & 114 & 421 \\
\hline Uppsala, Sweden ${ }^{a}$ [24] & 1989-1990 & $\geq 20$ & 130 & 463 \\
\hline Rochester, Minnesotab ${ }^{\mathrm{b}}$ [15] & 1975-1984 & $\geq 35$ & 127 & 428 \\
\hline Hvidovre, Danmark ${ }^{\mathrm{a}}$ [45] & 1976-1984 & $\geq 20$ & c & 397 \\
\hline Malmö, Sweden ad [9] & 1980-1981 & $\geq 20$ & 140 & 667 \\
\hline Hilleröd, Denmark ${ }^{\mathrm{a}}$ [11] & 1981 & $\geq 20$ & 90 & 350 \\
\hline Oslo, Norway ${ }^{\mathrm{a}}[40]$ & 1979 & $\geq 20$ & 169 & 673 \\
\hline Rochester, Minnesota ${ }^{\mathrm{b}}[15]$ & 1965-1974 & $\geq 35$ & 116 & 432 \\
\hline Rochester, Minnesota ${ }^{\mathrm{b}}[15]$ & 1955-1964 & $\geq 35$ & 65 & 364 \\
\hline Dundee/Oxford, UK ${ }^{\text {af }}$ [41] & 1954-1958 & $\geq 35$ & 81 & 313 \\
\hline Rochester, Minnesota $^{\mathrm{b}}[15]$ & 1945-1954 & $\geq 35$ & 65 & 393 \\
\hline Malmö, Sweden ad [2] & 1953-1957 & $\geq 20$ & 44 & 233 \\
\hline
\end{tabular}

Incidence per 100,000 py

${ }^{\text {a }}$ Crude incidence

${ }^{\mathrm{b}}$ Age standardized incidence

${ }^{\mathrm{C}}$ No male figures given

${ }^{\mathrm{d}}$ Numbers derived from Jónsson et al. [13]

${ }^{f}$ Numbers derived from Court-Brown et al. [41]

and this has been debated lately. Cost-benefit analyses have revealed small or no gains measured in Quality Adjusted Life Years (QALY) comparing volar plating procedures with other treatment options [34, 35].

With the expected demographic changes with a growing proportion of elderly citizens the number of fractures is likely to increase even if the fracture incidence, despite the findings in this study, should remain stable (Figs. 1 and 2). We have earlier found an increasing incidence also in distal forearm fractures in children [3]. As there are data supporting the idea that childhood fractures are forecasters of future fracture risk [36-38], our projections for the future may underestimate the future number of fractures especially as an incidence increase was also found in working ages in the current study. Interestingly, Mellstrand-Navarro et al. [19] reported that the rate of patients treated operatively with plating increased most (3-4 fold) from 2005 to 2010 in the age group $\geq 50$ years. As our findings suggest an over $50 \%$ increase in fractures in the population $\geq 65$ years until year 2050 it is of even more interest to make the treatment both evidence-based and as cost-effective as possible (Fig. 2). Therefore further studies are needed.

The strengths of our study include the coverage of a large adult population including all individuals in a welldefined geographical area during 12 years (11.2 million py) with validated data on distal forearm fractures [7]. However, the examination of registers rather than 
individual patients, charts or X-rays makes selection bias, random or systematic, possible. A previous validation of the register for this particular fracture type has however shown a very high accuracy [7]. Furthermore our results are very similar to those of Brogren et al. from Skåne region [22] and Flinkkilä et al. [16] from Finland who both utilized the gold standard of chart and X-ray review. Even though our case-finding strategy appears valid, estimations of absolute numbers from registers are always difficult. Relative changes (such as time trends) are however more easily subjected to examination and results more robust. We chose a wash-out period of one year, because the vast majority of all distal forearm fractures are then healed and thus, will not appear in the medical records again as a result of that fracture. If an individual appears in the register again, after more than a year with the same diagnosis, the most likely reason is a new fracture and the individual would then be included once more. Bilateral simultaneous fractures will however be counted only as one fracture, as the register does not include information about side. It would have been preferable with in-detail patient level data to identify possible explanatory factors.

\section{Conclusion}

The incidence of distal forearm fractures is increasing in both adult men and women in the Skåne region, Sweden. It is especially worrying that this seems driven by an increase in working ages (17-64 years) as this may present special challenges to both the healthcare system and loss of resources in society during time of sick-leave. The reasons for the increase in incidence are unknown and need further exploration but may include increasing prevalence of osteoporosis and overweight. We suggest similar examinations in other settings with uniform data collection and presentation to verify our results and to enable comparisons and merger of data. Collection and analysis of patient specific risk factors may provide additional insights to the origin of the changes. Cost analysis (including societal costs) and cost-benefit analyses of different treatments in both younger adults and elderly are scarce. Such data would contribute to understanding the effects of our findings and help decision makers to plan best use of resources in the future.

\section{Abbreviations}

BMD: Bone mineral density; BMI: Body mass index; Cl: Confidence interval; Py: Person-years; QALY: Quality adjusted life years; SHR: Skåne health care register

\section{Acknowledgements \\ Not applicable.}

\section{Funding}

Funding was received from the Swedish Research Council, from Government Funding of Clinical Research within the National Health Service (ALF), from FoU Skåne, from the Herman Järnhardt Foundation, from the Johan and Greta Kock Foundation, and from the Faculty of Medicine, Lund University, Sweden.

\section{Availability of data and materials}

The demographic data used for estimating the future number of fractures in Sweden is public and available at Statistics Sweden's website (www.scb.se). Fracture data were derived from the SHR, a registry that is not publicly available. We were granted ERB permission to an anonymous data set from this registry. Details on the data in the current study may, if not in conflict with the ERB permission, be available from the corresponding author on reasonable request.

\section{Authors' contributions}

$B R, M E$ and MK designed the study. BR and ME extracted the original data. $B R$ and DJ made all calculations. DJ wrote the first draft and edited the manuscript first together with BR and then together with all authors. All authors have read and revised the final manuscript. All authors read and approved the final manuscript.

\section{Competing interests}

The authors declare that they have no competing interests.

Consent for publication

Not applicable.

\section{Ethics approval and consent to participate}

The study was approved by the Lund University Ethical Committee. The need for individual informed consent was waived. The study was advertised in the major news papers where a possibility to opt-out was offered. This is a principle used in Sweden for population-wide studies using coded register data.

\section{Publisher's Note}

Springer Nature remains neutral with regard to jurisdictional claims in published maps and institutional affiliations.

\section{Author details}

${ }^{1}$ Clinical and Molecular Osteoporosis Research Unit, Departments of Clinical Sciences and Orthopedics Malmö, Skåne University Hospital, Lund University, SE 20502 Malmo, Sweden. ²Department of Clinical Sciences Lund, Orthopedics, Clinical Epidemiology Unit, Lund University, Faculty of Medicine, Lund, Sweden. ${ }^{3}$ Clinical Epidemiology Research and Training Unit, Boston

University School of Medicine, Boston, MA, USA.

Received: 16 February 2017 Accepted: 22 May 2017

Published online: 02 June 2017

\section{References}

1. Buhr AJ, Cooke AM. Fracture patterns. Lancet. 1959;1:531-6.

2. Alffram PA, Bauer GC. Epidemiology of fractures of the forearm. A biomechanical investigation of bone strength. J Bone Joint Surg Am. 1962:44-A:105-14.

3. Jerrhag D, Englund M, Petersson I, Lempesis V, Landin L, Karlsson MK, et al. Increasing wrist fracture rates in children may have major implications for future adult fracture burden. Acta Orthop. 2016;87:296-300.

4. Abrahamsen B, Jorgensen NR, Schwarz P. Epidemiology of forearm fractures in adults in Denmark: national age- and gender-specific incidence rates, ratio of forearm to hip fractures, and extent of surgical fracture repair in inpatients and outpatients. Osteoporos Int. 2015;26:67-76.

5. Wilcke MK, Hammarberg H, Adolphson PY. Epidemiology and changed surgical treatment methods for fractures of the distal radius: a registry analysis of 42,583 patients in Stockholm County, Sweden, 2004-2010. Acta Orthop. 2013;84:292-6.

6. Statistics Sweden. 1 May 2013 edition

7. Rosengren BE, Karlsson M, Petersson I, Englund M. The 21st-century landscape of adult fractures: cohort study of a complete adult regional population. J Bone Miner Res. 2015;30:535-42.

8. Statistics Swedens. 13 Feb 2017 edition.

9. Bengner $U$, Johnell $O$. Increasing incidence of forearm fractures. A comparison of epidemiologic patterns 25 years apart. Acta Orthop Scand. 1985;56:158-60

10. Miller SW, Evans JG. Fractures of the distal forearm in Newcastle: an epidemiological survey. Age Ageing. 1985;14:155-8. 
11. Solgaard S, Petersen VS. Epidemiology of distal radius fractures. Acta Orthop Scand. 1985;56:391-3.

12. Owen RA, Melton LJ 3rd, Johnson KA, Ilstrup DM, Riggs BL. Incidence of Colles' fracture in a North American community. Am J Public Health. 1982;72:605-7.

13. Jonsson B, Bengner U, Redlund-Johnell I, Johnell O. Forearm fractures in Malmo, Sweden. Changes in the incidence occurring during the 1950s, 1980s and 1990s. Acta Orthop Scand. 1999;70:129-32.

14. Lofthus CM, Frihagen F, Meyer HE, Nordsletten L, Melhuus K, Falch JA. Epidemiology of distal forearm fractures in Oslo, Norway. Osteoporos Int. 2008;19:781-6.

15. Melton LJ 3rd, Amadio PC, Crowson CS, O'Fallon WM. Long-term trends in the incidence of distal forearm fractures. Osteoporos Int. 1998;8:341-8.

16. Flinkkila T, Sirnio K, Hippi M, Hartonen S, Ruuhela R, Ohtonen P, et al. Epidemiology and seasonal variation of distal radius fractures in Oulu, Finland. Osteoporos Int. 2011;22:2307-12.

17. Sigurdardottir K, Halldorsson S, Robertsson J. Epidemiology and treatment of distal radius fractures in Reykjavik, Iceland, in 2004. Comparison with an Icelandic study from 1985. Acta Orthop. 2011;82:494-8.

18. Thompson PW, Taylor J, Dawson A. The annual incidence and seasonal variation of fractures of the distal radius in men and women over 25 years in Dorset, UK. Injury. 2004;35:462-6.

19. Mellstrand-Navarro C, Pettersson HJ, Tornqvist H, Ponzer S. The operative treatment of fractures of the distal radius is increasing: results from a nationwide Swedish study. Bone Joint J. 2014;96-B:963-9.

20. Curtis EM, van der Velde R, Moon RJ, van den Bergh JP, Geusens P, de Vries F, et al. Epidemiology of fractures in the United Kingdom 1988-2012: Variation with age, sex, geography, ethnicity and socioeconomic status. Bone. 2016;87:19-26.

21. Tsai CH, Muo CH, Fong YC, Lo WY, Chen YJ, Hsu HC, et al. A population-based study on trend in incidence of distal radial fractures in adults in Taiwan in 2000-2007. Osteoporos Int. 2011;22:2809-15.

22. Brogren $\mathrm{E}$, Petranek $\mathrm{M}$, Atroshi I. Incidence and characteristics of distal radius fractures in a southern Swedish region. BMC Musculoskelet Disord. 2007:8:48.

23. Cummings SR, Kelsey JL, Nevitt MC, O'Dowd KJ. Epidemiology of osteoporosis and osteoporotic fractures. Epidemiol Rev. 1985:7:178-208.

24. Mallmin H, Ljunghall S, Persson I, Naessen T, Krusemo UB, Bergstrom R. Fracture of the distal forearm as a forecaster of subsequent hip fracture: a population-based cohort study with 24 years of follow-up. Calcif Tissue Int 1993;52:269-72.

25. Kanis JA, Johnell O, De Laet C, Johansson H, Oden A, Delmas $P$, et al. A meta-analysis of previous fracture and subsequent fracture risk. Bone. 2004;35:375-82.

26. Rosengren BE, Ahlborg HG, Gardsell P, Sernbo I, Daly RM, Nilsson JA, et al. Bone mineral density and incidence of hip fracture in Swedish urban and rural women 1987-2002. Acta Orthop. 2010;81:453-9.

27. Rosengren BE, Ahlborg HG, Gardsell P, Sernbo I, Nilsson JA, Daly RM, et al, Forearm bone mineral density and incidence of hip fractures in Swedish urban and rural men 1987-2002. Scand J Public Health. 2012;40:102-8.

28. Ahlborg HG, Rosengren BE, Jarvinen TL, Rogmark C, Nilsson JA, Sernbo I, et al. Prevalence of osteoporosis and incidence of hip fracture in women-secular trends over 30 years. BMC Musculoskelet Disord. 2010;11:48.

29. Uusi-Rasi K, Karinkanta S, Heinonen A, Sievanen H. Improved femora neck BMD in older Finnish women between 2002 and 2010. Maturitas. 2013;75:241-5.

30. Looker AC, Melton LJ 3rd, Borrud LG, Shepherd JA. Changes in femur neck bone density in US adults between 1988-1994 and 2005-2008: demographic patterns and possible determinants. Osteoporos Int. 2012;23:771-80.

31. Johansson S, Wilhelmsen L, Welin C, Eriksson H, Welin L, Rosengren A. Obesity, smoking and secular trends in cardiovascular risk factors in middle-aged women: data from population studies in Goteborg from 1980 to 2003. J Intern Med. 2010;268:594-603.

32. Prieto-Alhambra D, Premaor MO, Fina Aviles F, Hermosilla E, Martinez-Laguna D, Carbonell-Abella C, et al. The association between fracture and obesity is site-dependent: a population-based study in postmenopausal women. J Bone Miner Res. 2012;27:294-300.

33. Borgstrom F, Zethraeus N, Johnell O, Lidgren L, Ponzer S, Svensson O, et al. Costs and quality of life associated with osteoporosis-related fractures in Sweden. Osteoporos Int. 2006;17:637-50.
34. Shauver MJ, Clapham PJ, Chung KC. An economic analysis of outcomes and complications of treating distal radius fractures in the elderly. J Hand Surg Am. 2011;36:1912-8. e1911-1913

35. Tubeuf S, Yu G, Achten J, Parsons NR, Rangan A, Lamb SE, et al. Cost effectiveness of treatment with percutaneous Kirschner wires versus volar locking plate for adult patients with a dorsally displaced fracture of the distal radius: analysis from the DRAFFT trial. Bone Joint J. 2015;97-B:1082-9.

36. Amin S, Melton LJ 3rd, Achenbach SJ, Atkinson EJ, Dekutoski MB, Kirmani S, et al. A distal forearm fracture in childhood is associated with an increased risk for future fragility fractures in adult men, but not women. J Bone Miner Res. 2013;28:1751-9.

37. Buttazzoni C, Rosengren BE, Tveit M, Landin L, Nilsson JA, Karlsson MK. Does a childhood fracture predict low bone mass in young adulthood? A 27-year prospective controlled study. J Bone Miner Res. 2013;28:351-9.

38. Farr JN, Khosla S, Achenbach SJ, Atkinson EJ, Kirmani S, McCready LK, et al Diminished bone strength is observed in adult women and men who sustained a mild trauma distal forearm fracture during childhood. J Bone Miner Res. 2014;29:2193-202

39. Cuenca J, Martinez AA, Herrera A, Domingo J. The incidence of distal forearm fractures in Zaragoza (Spain). Chir Main. 2003;22:211-5.

40. Falch JA. Epidemiology of fractures of the distal forearm in Oslo, Norway. Acta Orthop Scand. 1983:54:291-5.

41. Court-Brown CM, Biant L, Bugler KE, McQueen MM. Changing epidemiology of adult fractures in Scotland. Scott Med J. 2014;59:30-4.

42. Mallmin H, Ljunghall S. Incidence of Colles' fracture in Uppsala. A prospective study of a quarter-million population. Acta Orthop Scand. 1992;63:213-5.

43. O'Neill TW, Cooper C, Finn JD, Lunt M, Purdie D, Reid DM, et al. Incidence of distal forearm fracture in British men and women. Osteoporos Int. 2001;12:555-8.

44. Bentohami A, Bosma J, Akkersdijk GJ, van Dijkman B, Goslings JC, Schep NW. Incidence and characteristics of distal radial fractures in an urban population in The Netherlands. Eur J Trauma Emerg Surg. 2014;40:357-61.

45. Lauritzen JB, Schwarz P, Lund B, McNair P, Transbol I. Changing incidence and residual lifetime risk of common osteoporosis-related fractures. Osteoporos Int. 1993;3:127-32.

46. Dimai HP, Svedbom A, Fahrleitner-Pammer A, Resch H, Muschitz C, Thaler H et al. Epidemiology of distal forearm fractures in Austria between 1989 and 2010. Osteoporos Int. 2014;25:2297-306.

47. Diamantopoulos AP, Rohde G, Johnsrud I, Skoie IM, Hochberg M, Haugeberg G. The epidemiology of low- and high-energy distal radius fracture in middle-aged and elderly men and women in Southern Norway. PLoS One. 2012;7:e43367.

\section{Submit your next manuscript to BioMed Central and we will help you at every step:}

- We accept pre-submission inquiries

- Our selector tool helps you to find the most relevant journal

- We provide round the clock customer support

- Convenient online submission

- Thorough peer review

- Inclusion in PubMed and all major indexing services

- Maximum visibility for your research

Submit your manuscript at www.biomedcentral.com/submit 